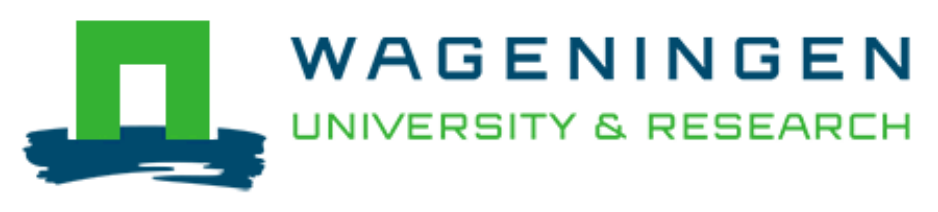

Increase of light transmission of a Venlo-type greenhouse during winter by 10\%: A design study

Kempkes, F., Swinkels, G. J., \& Hemming, S.

This is a "Post-Print" accepted manuscript, which has been published in "Acta Horticulturae"

This version is distributed under a non-commercial no derivatives Creative Commons

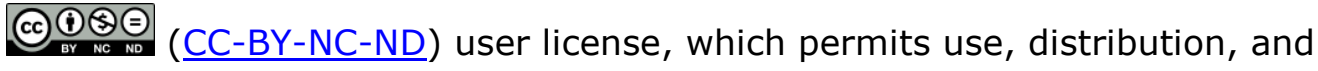
reproduction in any medium, provided the original work is properly cited and not used for commercial purposes. Further, the restriction applies that if you remix, transform, or build upon the material, you may not distribute the modified material.

Please cite this publication as follows:

Kempkes, F., Swinkels, G. J., \& Hemming, S. (2018). Increase of light transmission of a Venlo-type greenhouse during winter by $10 \%$ : A design study. Acta Horticulturae, 1227, 133-140. DOI: 10.17660/ActaHortic.2018.1227.16

You can download the published version at:

https://doi.org/10.17660/ActaHortic.2018.1227.16 


\title{
Increase of light transmission of a Venlo-type greenhouse during winter by 10\%: a design study
}

F. Kempkesa, G.J. Swinkels, S. Hemming.

Wageningen University \& Research, Greenhouse Horticulture, Wageningen, The Netherlands.

\begin{abstract}
During winter period and at higher latitudes, natural light is the limiting factor for crop growth in greenhouses. Design of Venlo-type greenhouses in The Netherlands has not changed for many years although recent developments of diffuse glass with anti-reflective coatings might cause a need to alter the roof design for maximized light transmissivity during winter period. Light transmissivity of a greenhouse, in general, is influenced by roof slope, gutter orientation, roof shape, dimensions, position and reflectivity of construction elements, screen installation, position and transmissivity of screen material, transmissivity and light scattering pattern of the covering and the effect of condensation at the inner side of the covering material or screen. With the raytracing model RAYPRO (Swinkels et al., 2001) the integral effect of all individual and combined measures on light transmission of the greenhouse at crop level were calculated. Results show that it is possible to increase light transmission more than $10 \%$ with a novel greenhouse roof concept. Results of the ray-tracing calculations for individual and combined measures are described in this paper.

After identifying the roof concept with the theoretically highest increase in light transmissivity during winter period in The Netherlands, economic feasibility and all constructional restrictions were taken into account in close cooperation with industrial partners. This has led to a novel roof design which was built aa demonstration greenhouse on a scale of $500 \mathrm{~m}^{2}$ in summer 2016 at Wageningen University \& Research station in Bleiswijk. The "Winterlight Greenhouse" had resulted in a re-design of traditional Venlo type greenhouse roof, covering and screen.
\end{abstract}

Keywords: greenhouse design, covering material, coatings, diffuse light, energy efficiency

\section{INTRODUCTION}

Especially during winter months, it is important to achieve high crop production with high quality. During this period, product prices are generally high, therefore, winter production is important for growers. In the Netherlands, the average solar radiation sum in winter is ten times lower than in the summer leading to light being a limiting growth factor. Nevertheless, it is important to utilize the available natural light as much as possible for crop production. Research by Marcelis et al. (2014) has shown that especially in winter, $1 \%$ more light gives $0.8-1 \%$ more production for cucumber. In earlier studies Hemming et al. (2004) showed the importance of optimum use of natural light. Janssen et al. (2006) carried out calculations on the effect of greenhouse shape on light transmission. The importance of diffuse light and diffuse coverings has been shown in various studies for various crops (e.g. Hemming et al., 2008; Dueck et al., 2012; Li et al., 2014.). The role of light increasing antireflection coating for horticultural glass has been described by Hemming et al. (2011) and the effect of condensation against the greenhouse cover has earlier been investigated by Stanghellini et al. (2012).

Natural sunlight is for free and should be used as much as possible for crop production in greenhouses (Hemming et al., 2004). Especially during winter, every Joule of sunlight is

a Frank.Kempkes@wur.nl 
free energy input into the greenhouse reducing heating costs. The amount of light available to the crop in winter depends on many factors interacting with each other. These factors are:

Greenhouse design (roof slope, gutter orientation, roof shape, dimensions, position and reflectivity of construction elements); Layout of the greenhouse (installations in the roof section such as screen installation, position and transmissivity of screen material); Covering material (transmissivity and light scattering pattern of the covering); Type of condensation at the inner side of the covering material or screen. After natural light has entered the greenhouse crop parameters such as plant structure, plant development stage and leaf area index, plant spacing and crop orientation also have a major impact on light interception. However, this study focusses on light entering the greenhouse roof, crop effects are not described. Furthermore, this study focuses mainly on diffuse covering materials.

After an intensive optical modelling study of above mentioned single and combined factors with ray-tracing models a theoretically optimum greenhouse roof design has been identified. Afterwards, a consortium of greenhouse suppliers (greenhouse construction, glass and coatings, screens and breeder) developed and built the new "Winter light greenhouse". The goal was to gain at least $10 \%$ more natural light in winter (October - March) inside the greenhouse. In this paper, the results of the optical calculations to develop and finally build the winter light greenhouse to maximize light entrance during winter are presented.

\section{MATERIALS AND METHODS}

\section{Ray-tracing model}

The simulation model RAYPRO is based on non-sequential light-based ray-tracing and calculates light paths in a 3D environment. The model is developed by Wageningen University \& Research with focus on greenhouse applications. The model used is evolved, validated and used to design new greenhouse concepts such as electricity producing greenhouses with NIR filtering (Sonneveld et al., 2010), greenhouses with Fresnel lenses (Sonneveld et al., 2011), surface structures for increasing light transmissivity and scattering (Swinkels et al., 2001) and bio reactors for algae production. There are some key features which make RAYPRO a suitable model for these kinds of issues. To discard boundary effects like the greenhouse facade, the object can be simulated as infinite large (Figure 1).

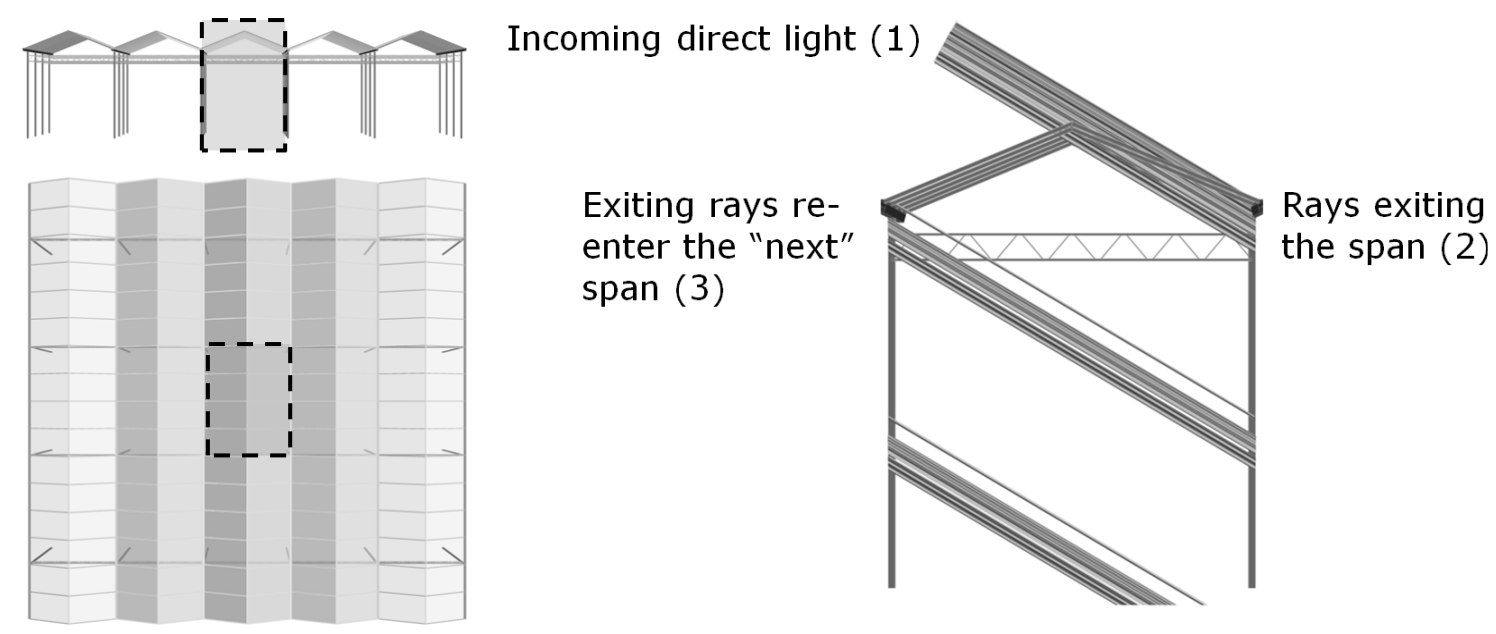

Figure 1. An infinite large greenhouse is simulated by regarding the smallest repeating unit (one span $\times$ one section) as scene boundaries and re-enter rays which leave the scene from the opposite site. 
Measured optical material properties such as transmissivity, reflectivity and spatial scattering, can be imported into the model. Transmissivity and reflectivity as a function of wavelength and angle of incidence are used, scattering properties are used as Bidirectional Scattering Distribution Function data (BSDF) for all angles of incidence and for forward as well as backward scatter. All materials used in the study were measured by WUR LightLab using the IS-SA ${ }^{\mathrm{TM}}$ Integrating sphere (Radiant) for scattering measurements and the Transvision integrating sphere for transmissivity (Swinkels, 2012). With the model the individual and integral effects of diffuse covering materials, screen materials, greenhouse orientation, roof shape (symmetric, saw tooth, convex, concave), roof slope, optical properties of the constructional parts, anti-reflection (AR) coatings, condensation on the inside of the covering material can be described. The design of the constructional parts was no primary subject for investigation and had in all calculations the same dimensions. Results were compared based on the daily light sum inside the greenhouse during the period October March and the typical winter month January for all scenario calculations.

\section{Reference greenhouse}

All scenarios where compared to the reference greenhouse, which is defined as a Venlo type greenhouse of infinite size with a roof slope of $23^{\circ}$, standard construction elements (gutter, ridge, glazing bars only) two $4 \mathrm{~m}$ roofs on an $8 \mathrm{~m}$ trellis bar and all dimensions of these construction parts were kept the same for all calculations and standard clear uncoated greenhouse glass. To discard the effect transmissivity of materials when comparing cases with clear (perpendicular light transmissivity of 90.4 and hemispheric $82.9 \%$, with a haze of $<1 \%$ ) and diffuse (perpendicular light transmissivity of 93.6 and hemispheric $82.9 \%$, with a haze of $71 \%$ ) materials the transmissivity values were kept equal.

\section{Construction Materials}

Aluminium is the starting point for all structural components in the roof construction with a reflectivity of $60 \%$ and the distribution of the light reflected is dependent on the angle of incident. In some scenario's, the effect of a powder coated construction elements is calculated. Hereby, the angle-dependent reflectivity is equal to that of a Lambertian diffuser (Bi-directional Transmittance Distribution Function, BTDF of 100\%), so a homogeneous distribution of the light and has a reflectivity of $83 \%$.

\section{Condensation}

Condensation results from the fact that the surface temperature of an object falls below the dew point temperature of the greenhouse air. Form of the condensation (drops or film formation) and the amount present at the cover are dependent on the surface properties of the material. Quantification of the form and amount of condensate is not part of this study. For the study the effects of condensation on the transmissivity is measured for a dry and wet material and used for calculation.

\section{RESULTS}

\section{Reference}

The results show that for the reference Venlo cover with an East-West oriented gutter $\left(0^{\circ}\right)$ with a slope of $23^{\circ}, 75.6 \%$ of the total incoming PAR is transmitted during the period October to April and $72.9 \%$ during January when covered with clear glass. Results for diffuse glass are for the winter period October-March $0.6 \%$ lower due to an additional upward scattering of the transmitted light although January shows a slight increase. However, a NorthSouth oriented gutter $\left(90^{\circ}\right)$ reduces incoming PAR by around $2 \%$. In figure 2 the results of the reference greenhouse with clear and diffuse glass and its orientation (E-W: $0^{\circ} \& \mathrm{~N}-\mathrm{S}: 90^{\circ}$ ) are shown for a year and different periods. 

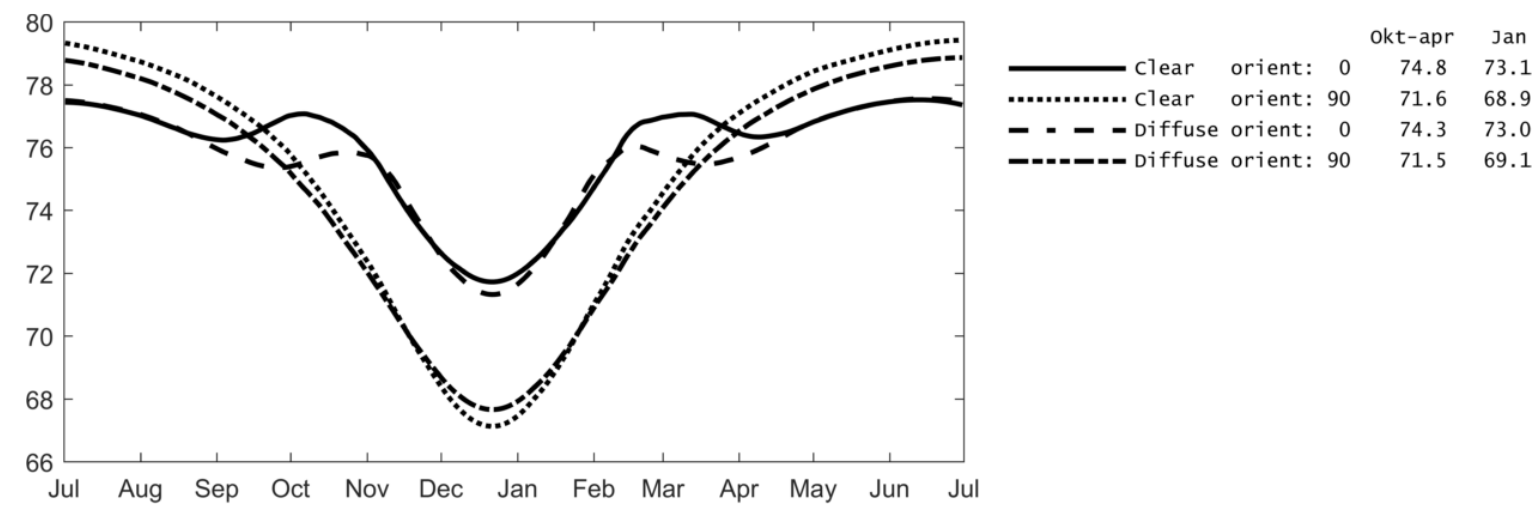

Figure 2. Transmissivity of the Venlo reference greenhouse with a $23^{\circ}$ roof slope and its construction elements covered with clear or diffuse glass for two different roof orientations $\left(0^{\circ}=\right.$ East-West and $90^{\circ}=$ North-South $)$.

A diffuse cover material has a principally negative effect on light transmissivity at a roof slope greater than zero. This effect is independent of the angular transmissivity of the material and is caused by an additional upward scattering of the transmitted light, which is not apparent in clear glass. With a E-W oriented roof and a slope of around $23^{\circ}$ this effect is limited to $0.6 \%$ loss for the winter period. Depending on the roof orientation and slope, the adverse effect of diffuse glass can rise up to $6 \%$ in January (data not shown).

A reference orientation of $0^{\circ}$ (East-West) is the most favourable one for the reference greenhouse. In detailed calculations (data not shown) it was found that the construction always has a major influence on the transmissivity. Approximately $10 \%$ points and $8 \%$ points additional light interception in the greenhouse with a clear and diffuse covering material, respectively. The greenhouse construction reduces the difference between clear and diffuse glass because the constructional parts themselves also scatter light (upwards). At low solar elevations in January, the upward scattering caused by the constructional parts is greatest and hence the difference between clear and diffuse glass is lowest.

\section{Effect of the roof slope}

If the construction parts are not included in the calculations, for both a clear and diffuse material, the transmissivity increases with an increasing roof slope. However, the above mentioned upwards scattering will always be unfavourable for diffuse materials. When construction parts are taken into account, for a clear material, the optimal roof slope is found at around $30^{\circ}$ for a clear material and for a diffuse material around $20^{\circ}$ (data not shown).

\section{Effect of roof orientation}

When a surface parallel to the earth's surface, the azimuthal orientation of this surface does not affect the solar angle of incidence on this surface and consequently the transmissivity. However, in a Venlo type greenhouse roof with roof slopes around $23^{\circ}$, the angle of incidence depends on the greenhouse orientation. In January a $\mathrm{N}-\mathrm{S}$ orientation reduces light transmissivity by $4 \%$ against E-W (clear glass). During the months October-March this difference is $2.1 \%$ for a diffuse and $2.6 \%$ for a clear material. On a yearly basis the total light gain of a N-S oriented roof is higher, but since natural light is the limiting factor for crop production in winter an E-W orientation is favourable for clear as well as diffuse materials.

\section{Effect of an asymmetrical greenhouse roof}

Simulations were made for an asymmetric roof with a gutter-ridge height of $0.85 \mathrm{~m}$ and $4 \mathrm{~m}$ span width. At constant gutter-ridge height southern and northern roof slopes were varied following the principle showed in Figure 3. 


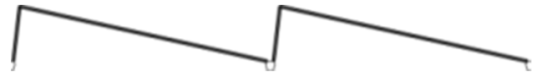

16
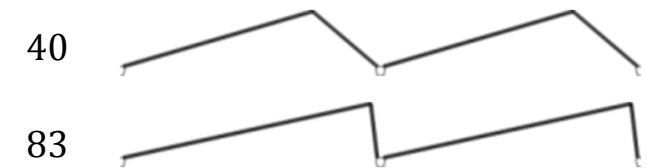

Figure 3. Asymmetrical greenhouse roof with equal gutter-ridge height of $0.85 \mathrm{~m}$ and various Northern and Southern roof slopes.

The results show that an E-W oriented saw tooth roof increases transmissivity up to $2.5 \%$ in January (reference is $23^{\circ} \mathrm{N}$ and $23^{\circ} \mathrm{S}$ ). In figure 4 the effects on light transmissivity throughout the year are shown for different roof slope combinations. In this figure construction elements are equal for all combinations. All calculations were done with a clear covering.
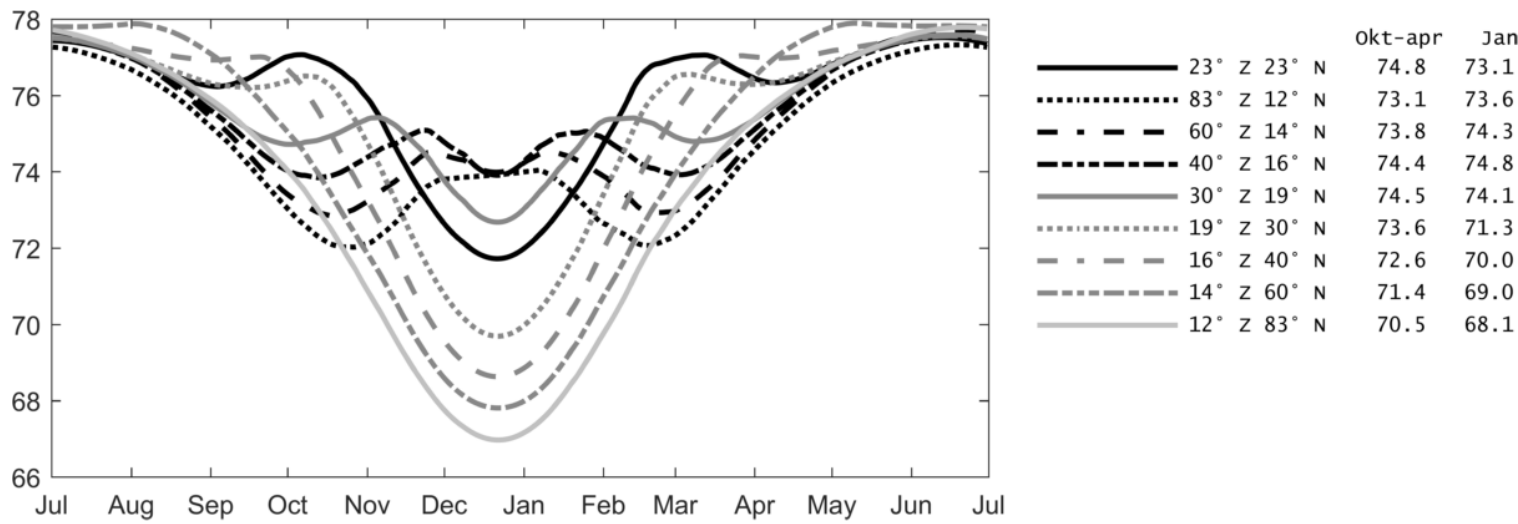

Figure 4. Effect of asymmetric roof shape with various northern and southern roof slopes on greenhouse transmissivity throughout the year for a E-W orientation and a clear covering.

\section{Effect of an asymmetrical saw tooth roof}

Starting point for the calculations with the asymmetrical saw tooth roof are a vertical roof on the southern pane and a variable slope on the northern pane, which will change the gutter-ridge height with a constant span width of $4 \mathrm{~m}$. The results of these calculations are shown in figure 5. A saw tooth roof with the vertical pane on the southern side and a northern slope of $15^{\circ}$ increases transmissivity theoretically with $3 \%$ for a diffuse covering material during January.
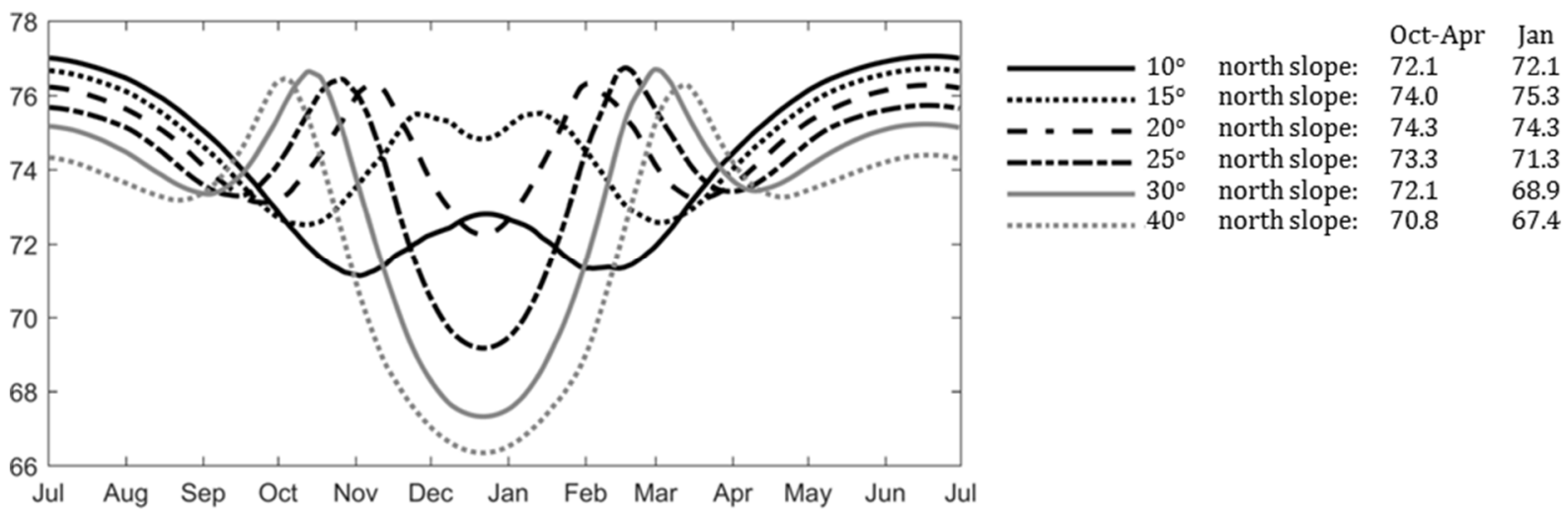

Figure 5. Effect of asymmetric saw tooth roof with vertical pane to the south and various roof slopes on north side. 


\section{Effect of optical properties of construction elements}

By improving the reflectivity properties of the construction parts light transmissivity could be increased. Calculations showed that a $99 \%$ specular reflective construction $(99 \%$ reflectivity) increases transmissivity with 8 to $10 \%$ in winter compared to aluminized construction with a total reflectivity of $65 \%$ with a large diffuse part. In case of diffuse materials the effects are a few percent lower.

\section{Effect of condensation on the cover}

In winter at Northern latitudes in general the greenhouse cover will wet due to condensation. Measuring the optical properties of wet glass is complicated. Based on earlier measurements of Stanghellini et al. (2012) and additional indicative measurements of the angular light transmissivity of wet and dry materials at WUR LightLab (data not shown), it can be concluded that a clear glass without coating often shows an unfavourable condensation behaviour (droplets) which reduces light transmissivity. Several diffuse glasses (all AR coated) show a favourable condensation form (water film) with unchanged or increased light transmissivity. Hydrophilic coatings can have a neutral or positive impact on transmissivity, whereas hydrophobic coatings can have a negative impact. Under practical conditions the greenhouse glass is wet most of the time during winter, under these conditions chosen diffuse glass realizes 6 to $7 \%$ more transmissivity compared to the reference material if wet.

\section{Winter light greenhouse}

By combining the insights from the above paragraphs, the most favourable greenhouse roof design for the winter period would be a saw tooth greenhouse roof with $25^{\circ}$ slope on the North side, with perfect specular reflective construction elements and hydrophilic diffuse glass with AR treatment in order to maximise natural light usage. This roof increases light transmissivity with 13 and 14\% points in respectively October -March and January. During the practical design by the industrial partners, including (legislation on) wind load, snow load and asymmetric forces, it appeared that the greenhouse construction had to be changed in such a way that the theoretical gain was more limited.

Because the greenhouse should be commercially viable it was decided to redo the design process of the winter light greenhouse with the knowledge of the previous calculations. Without any discussion roof orientation $(\mathrm{E}-\mathrm{W}]$ and roof slope of $23^{\circ}$ are copied. At first, the gutter distance was scaled up from $4.00 \mathrm{~m}$ (reference) to $5.60 \mathrm{~m}$ to maximize the glass panel size of approximately $3.00 \times 1.67 \mathrm{~m}$. For this the glass thickness had to be increased from 4 to $5 \mathrm{~mm}$. While gutter and bar dimensions had only slightly to be adapted, increase of the gutter distance up to 5.60 gained around $0.3 \%$ on the transmissivity of the cover. The consortia members have provided new glass, screen cloth with improved transmissivity under dry and wet conditions and improved powder coating to enhance the reflectivity of construction elements. All properties were all measured at WUR LightLab. The reference materials are standard (std) glass with $82.9 \%$ hemispherical transmissivity, a standard Luxous 1347 screen with $72 \%$ hemispherical transmissivity, a white powder coated steel construction with a reflectivity of $82 \%$ and aluminium profiles in the roof with a reflectivity of $65 \%$. The supplied new materials showed a hemispherical transmissivity of $91 \%$ for the glass, $76 \%$ for the screen and a reflectivity of $87 \%$ of the powder-coated construction elements. The overall transmissivity of the New IDC greenhouse was calculated.

To reduce the energy consumption of this greenhouse, a double independent controllable screen with a $5 \mathrm{~cm}$ split in between was used. In the reference greenhouse this is a double horizontal screen, in the new IDC greenhouse the two screens are installed under an angle equal to the roof slope (Figure 6) to increase transmissivity during winter months. 

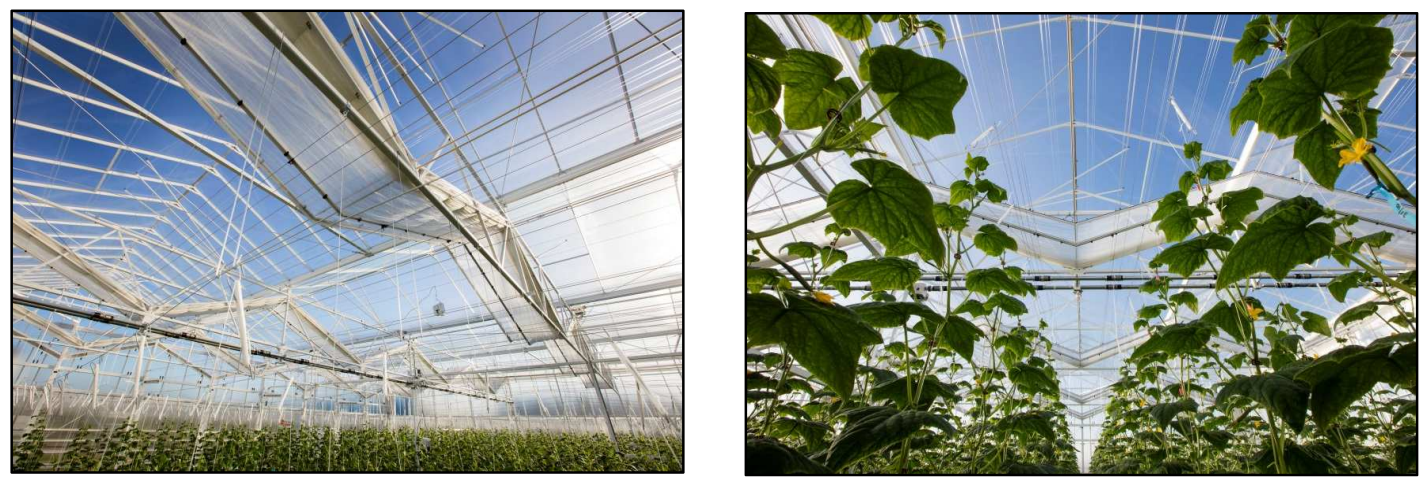

Figure 6. Photos of the final Winter light greenhouse with a partly closed W shaped double screen.

The calculation results, Table 1, show that the IDC greenhouse with new glass, screens and increased reflectivity of the entire construction would achieve a light gain of $11.8 \%$ in winter with respect to the reference greenhouse (Ref). On base of these results the decision was made to use this design for the full-scale greenhouse. In the process of upscaling the R\&D samples of glass and screen cloth from the lab size to the production, about $1 \%$ of transmissivity in screen cloth and glass and $2 \%$ in reflectivity of the construction have been lost, but the final result is still a $10.5 \%$ light gain in winter when the cover is wet and both screens are closed. Table 1 shows as well that light gains in winter are also positive in summer.

Table 1. Overview of the calculations of the light transmissivity of the reference and IDC greenhouse with standard, improved and final materials during winter (OctoberMarch), summer (April-September) and January.

\begin{tabular}{|c|c|c|c|c|c|c|}
\hline Scenario & & iter & & uary & & imer \\
\hline Ref, std glass (82.9\%), screen open & 72.6 & & 70.3 & & 73.6 & \\
\hline IDC, std glass (82.9\%), screen open & 73.6 & +1.0 & 71.7 & +1.4 & 74.4 & +0.8 \\
\hline IDC, new glass (91\%), screen open & 79.9 & +7.2 & 77.7 & +7.4 & 81.0 & +7.5 \\
\hline $\begin{array}{l}\text { Ref, std glass ( } 82.9 \%) \text { - double Luxous1347 (72\%), } \\
\text { screen closed }\end{array}$ & 41.2 & & 39.1 & & 43.5 & \\
\hline $\begin{array}{l}\text { IDC, std glass (82.9\%) - double Luxous1347 (72\%), } \\
\text { screen closed }\end{array}$ & 44.8 & +3.6 & 43.5 & +4.4 & 45.8 & +2.2 \\
\hline $\begin{array}{l}\text { IDC, std glass }(82.9 \%) \text { - double new screen }(76 \%) \text {, } \\
\text { screen closed }\end{array}$ & 49.0 & +7.8 & 47.6 & +8.5 & 50.0 & +6.5 \\
\hline $\begin{array}{l}\text { Ref, std glass }(82.9 \%) \text {, condensation incl., screen } \\
\text { open }\end{array}$ & 68.4 & & 66.3 & & 70.4 & \\
\hline IDC, new glass (91\%), condensation incl., screen open & 78.6 & +10.1 & 76.7 & +10.4 & 80.0 & +9.6 \\
\hline $\begin{array}{l}\text { Ref, std glass (83\%), double Luxous1347 (72\%), } \\
\text { screen closed }\end{array}$ & 39.6 & & 37.7 & & 42.2 & \\
\hline $\begin{array}{l}\text { IDC, new glass }(91 \%) \text {, double new screen }(76 \%) \text {, } \\
\text { condensation incl., screen closed }\end{array}$ & 51.4 & +11.8 & 50.0 & +12.4 & 52.9 & +10.7 \\
\hline $\begin{array}{l}\text { IDC, final glass }(90 \%) \text {, double final screen }(75 \%) \text {, } \\
\text { condensation incl., screen closed }\end{array}$ & 50.1 & +10.5 & 48.7 & +11.0 & 51.5 & +9.3 \\
\hline
\end{tabular}

\section{CONCLUSIONS}

It can be concluded that ray-tracing models are good tools to theoretically study the effect of different greenhouse roof parameters on natural light transmissivity separately and 
combined. After redesigning the Venlo greenhouse taking into account commercial considerations the increase in light transmissivity of the new greenhouse was $10.5 \%$ during winter. For this two roofs of $5.6 \mathrm{~m}$ were placed on a trellis bar of $11.2 \mathrm{~m}$ with highly transparent diffuse glass by etching with a panel size of $1.67 \mathrm{~m}$ by $3 \mathrm{~m}$ and a hemispherical transmissivity of $90.5 \%$, complete white painted roof construction elements with a high reflectivity of $85 \%$ and a double highly transparent woven movable screen with a hemispherical transmissivity of $79 \%$ installed under an angle of $20^{\circ}$. Currently, experimental data is collected in the realised demonstration greenhouse including the data and performance of a cucumber crop.

\section{ACKNOWLEDGEMENTS}

The research is carried out together with a consortium of greenhouse suppliers: Bom Group, Glascom, Bayer and Ludvig Svensson and is co-financed by the Dutch Ministry of Economic Affairs in the scope of the Dutch research programme for energy saving 'Kas als Energiebron'. Special thanks to WUR LightLab (Vida Mohammadkhani and Bram van Breugel).

\section{LITERATURE CITED}

Bot, G.P.A. (1983). Greenhouse climate: from physical processes to a dynamic model. Ph.D. Disertation. Agriculural University, Wageningen, $240 \mathrm{pp}$.

Dueck, T.A., Janse, J., Li, T., Kempkes, F.L.K., and Eveleens-Clark, B.A. (2012). Influence of diffuse glass on the growth and production of tomato. Acta Hort. 956, 75-82 http://dx.doi.org/10.17660/ActaHortic.2012.956.6

Hemming, S., Waaijenberg, D., Bot, G.P.A., Dueck, T., Dijk, C. Van, Dieleman, A., Rijssel, E. Van, Houter, B., Sonneveld, P.J., Zwart, H.F. de, Marissen, N. (2004). Optimale lichtomstandigheden bij de transitie naar een energiezuinige kastuinbouw. WUR Report 100, Agrotechnology and Food Innovations.

Hemming, S., Dueck, T.A., Janse, J. and Noort, F.R. van. (2008). The Effect of Diffuse Light on Crops. Acta Hort. 801, 12931300 http://dx.doi.org/10.17660/ActaHortic.2008.801.158

Hemming, S., Kempkes, F.L.K., and Mohammadkhani, V. (2011). New glass coatings for high insulating greenhouses without light losses - energy saving crop production and economic potentials. Acta Hort. 893, 217-226 http://dx.doi.org/10.17660/ActaHortic.2011.893.15

Janssen, E.G.O.N., Oversloot, H., Wiel, W.D. van der, Zonneveldt, L. (2006). Optimaal kasdek TNO-rapport 2004-BC-R0060.

Li T., Heuvelink E., Dueck T.A., Janse J., Gort G., and Marcelis L.F.M. (2014). Enhancement of crop photosynthesis by diffuse light: quantifying the contributing factors. Ann. Bot. 114, 145-156. http://dx.doi.org/10.1093/aob/mcu071

Marcelis, L.F.M., Buwalda, F., Dieleman, J.A., Dueck, T.A., Elings, A., Gelder, A. de, Hemming, S., Kempkes, F.L.K., Li, T., Noort, F. van and Visser, P.H.B. de (2014). Innovations in Crop Production: A Matter of Physiology and Technology. Acta Hort. 1037, 39-46. http://dx.doi.org/10.17660/ActaHortic.2014.1037.1

Sonneveld, P.J., Swinkels, G.L.A.M., Bot, G.P.A., and Flamand, G. (2010). Feasibility study for combining cooling and high grade energy production in a solar greenhouse, Biosystems Engineering. 105, 51-58. http://dx.doi.org/10.1016/j.biosystemseng.2009.09.012

Sonneveld, P.J., Swinkels, G.L.A.M. ,Tuijl, B.A.J. van, Janssen, H.J.J., Campen, J., and Bot, G.P.A. (2011). Performance of a concentrated photovoltaic energy system with static linear Fresnel lenses. Solar Energy. 85(3), 432-442 http://dx.doi.org/10.1016/j.solener.2010.12.001

Stanghellini, C., Bruins, M.A., Mohammadkhani, V., Swinkels, G.L.A.M., and Sonneveld, P.J. (2012). Effect of condensation on light transmission and energy budget of seven greenhouse cover materials. Acta Hort. 952, 249-254 http://dx.doi.org/17660/ActaHortic.2012.952.30

Swinkels, G.L.A.M., Sonneveld, P.J., and Bot, G.P.A., (2001). Improvement of Greenhouse Insulation with Restricted Transmission Loss through Zigzag Covering Material. Journal of Agricultural Engineering Research. 79 (1). 91-97 https://doi.org/10.1006/jaer.2000.0676

Swinkels, G.L.A.M., 2012. Transvision: a Light Transmission Measurement System for Greenhouse Covering Materials. Acta Hort. 956, 563-568 http://dx.doi.org/10.17660/ActaHortic.2012.956.67 